\title{
Identification by Docking Simulation and in vivo Effect of Essential Oil from Cinnamommum burmannii as Anti-obesity with Leptin Receptor in the Olfactory System of Mice Balb C
}

\author{
Kusmardi Kusmardi ${ }^{1}$, Aryo Tedjo², Fadilah Fadilah ${ }^{2}$, Ade Arsianti ${ }^{2}$, Rafika Indah Paramita ${ }^{2 *}$
}

\section{Kusmardi Kusmardi ${ }^{1}$, Aryo Tedjo², Fadilah Fadilah², Ade Arsianti ${ }^{2}$, Rafika Indah Paramita $^{2 *}$}

\section{'Department of Anatomical Pathology,} Faculty of Medicine, University of Indonesia, Jakarta - 10430, INDONESIA.

${ }^{2}$ Department of Medical Chemistry, Drug Development Research Center - IMERI, Faculty of Medicine, University of Indonesia, Jakarta-10430, INDONESIA.

\section{Correspondence}

Rafika Indah Paramita

Department of Medical Chemistry, Drug Development Research Center - IMERI, Faculty of Medicine, University of Indonesia, Jakarta - 10430, INDONESIA.

Phone no: +62-21-31930302

E-mail: fika.paramita@gmail.com

\section{History}

- Submission Date: 29-12-2017;

- Review completed: 14-02-2018;

- Accepted Date: 05-03-2018

DOI : 10.5530/pj.2018.5.147

Article Available online http://www.phcogj.com/v10/i5

\section{Copyright}

(C) 2018 Phcog. Net. This is an openaccess article distributed under the terms of the Creative Commons Attribution 4.0 International license.

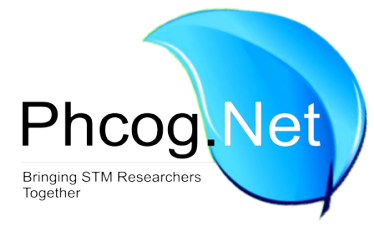

\begin{abstract}
Aim: This study examines the effect of inhalation of essential oil of cinnamon (Cinnamomum burmannii) on the metabolic activity of hormone receptors olfactory system of mice Balb $\mathrm{C}$. Methodology: Effects of agonist or antagonist compounds in cinnamon essential oil on metabolic hormone receptors in the olfactory system are predicted using molecular docking simulation. Changes in the metabolic processes that occur views of changes in body weight, change in food intake, as well as lipid profile and blood glucose of mice. Result: The results showed Expression of leptin receptors (Lep-R) in the brains of mice given either inhalation of essential oils derived from the leaves and stems, in contrast to the control group who did not get essential oils. Provision of essential oils through inhalation increased lep- $R$ expression in the brain of mice. Both in silico and in vivo evidence that essential oils from cinnamon plants are extracted from Cinnamommum burmannii and given by inhalation in Balb C mice are known to improve glucose and lipid metabolism by reducing the concentration of serum leptin concentrations and increased sensitivity to insulin.
\end{abstract}

Keywords: Olfactory system, Leptin receptors, Cinnamomum burmannii, Docking simulation, immunohistochemistry.

\section{INTRODUCTION}

The general prevalence of adult obesity nationally in Indonesia is $19.1 \%$ ( $8.8 \%$ obese and $10.3 \%$ more obese), and the prevalence of central obesity to the national level is $18.8 \%{ }^{1}$ While data 2015 showed a general prevalence of adult obesity increased to $21.7 \%$ which is a combination of the obesity. In children, the greatest prevalence of obesity was found in infants at 14 $\%$, and the smallest at the age of $16-18$ is equal to $1.4 \%{ }^{2}$ Obesity increases the risk for a number of serious comorbidities and often fatal as non-insulin dependent diabetes mellitus (NIDDM), dyslipidemia, cardiovascular disease, osteoarthritis, and certain types of cancers such as colon cancer and breast cancer post menopause. ${ }^{3,4}$

Obesity is a multifactorial condition. Such factors include genetic factors, diet, psychological states such as stress, physical activity, and factors related to the mechanism of the brain or the so-called cognitive factors and factors sensor. ${ }^{5}$ Appetite initiated by smell (odor) works the olfactory system. Olfactory system is a sensor system (sensory) operating after the start of the transduction of chemical smells (odorants) to the occurrence of an action potential and limbic mechanisms that regulate and direct the behavior of

a deliberate and need information of odor. ${ }^{6}$ Smell is one of the primary senses that contribute to hedonic evaluation of food, thus affecting individuals in the selection and consumption of food. In the study in children aged 8-12 years with overweight shows that the trend patterns of overeating at the age of overstimulation triggered by their sense of smell by the smell of food compared to the factor-psychological factors such as mood, body esteem (assessment and acceptance of one's own body), and uncontrolled eating styles after chronic dietary/resist the urge to eat (restrained eating style). ${ }^{7}$

Compounds odorant (smell) work on the olfactory system. In the olfactory system, there are many receptors are associated with the metabolic hormones that play a role in regulating appetites such as insulin, leptin, and ghrelin. Currently, it is known that in addition to regulating appetite, hormones that work on the olfactory system also plays a role in the metabolism of nutrients. In the other study obtained by the fact that rats were given leptin - a hormone anorexigenic (appetite-suppressing hormone) - exogenous via intracerebroventricular (ICV) decreased body weight and

Cite this article: Kusmardi K, Tedjo A, Fadilah F, Arsianti A, Paramita RI. Identification by Docking Simulation and in vivo Effect of Essential Oil from Cinnamommum burmannii as Antiobesity with Leptin Receptor in the Olfactory System of Mice Balb C. Pharmacog J. 2018;10(5):875-9. 
food intake significantly within $48 \mathrm{hr}^{8}$ Another study by Keung et al (2011) showed that administration of exogenous leptin via ICV in obese mice (mice were given a high-fat diet) then play to lose weight and food intake, it also served to increase fatty acid oxidation, and increased tolerance glukosa. ${ }^{9}$

In this research, immunohistochemical methods will be used to see on the metabolic activity of hormone receptors olfactory system Balb C after being given the essential oils from bark and leaves of the plant cinnamon (Cinnamomum burmannii) via inhalation. Metabolic hormone receptor activity in the olfactory system by the response observed secretion (a protein) that is produced due to the hormone-receptor binding in the hypothalamus. In the previous studies note that some essential oils are given to animals orally try to influence the process of metabolism (glucose and lipid profile) from rats/mice or rabbits induced diabetic stress oxidative. ${ }^{11-13}$ Plant cinnamon is used as in previous studies note that the oil essential extracted from cinnamomi cortex and given orally in mice that are resistant to insulin is known to improve glucose and lipid metabolism by reducing the concentration of serum leptin concentrations and increased sensitivity to insulin. ${ }^{14-15}$

Effect of essential oils cortex in influencing metabolic processes has been empirically proven. However, what about the effect of essential oils via inhalation in influencing hormone-receptor binding in the olfactory system is not yet known. Though based on a study conducted by Peters et al (2007), Keung et al (2011), and Schulz et al (2012) note that the metabolic hormone (leptin) that works directly on the hypothalamus starts the process of interaction that occurs between the lep- $\mathrm{R}$ in system olfaktori. ${ }^{8-10}$ Given these facts , this study aims to look at the effect of inhalation of essential oil of cinnamon (Cinnamomum burmannii) on the metabolic activity of hormone receptors Balb $\mathrm{C}$ mice olfactory system by the protein that is secreted in the hypothalamus using immunohistochemistry method.

\section{MATERIALS AND METHODS}

\section{Isolation of Essential Oils}

Isolation of essential oils from botanicals cinnamon bark and leaves is done by using water distillation system Stahl. Simplicia dry powder of cinnamon bark and leaf inserted in a round pumpkin measuring $2 \mathrm{~L}$. Next distilled water added with a ratio of $1: 2(\mathrm{w} / \mathrm{v}, \mathrm{g}$ powder/ $\mu \mathrm{l}$ distilled water). The distillation is carried out for $6 \mathrm{hr}$ at temperatures ranging from $100-105^{\circ} \mathrm{C}$. Distillation produced a mixture of oil and distilled water. The two are separated after the mixture was placed in a separating funnel and allowed to stand for $24 \mathrm{hr}$. Separate oil included in the sample container to be used in the subsequent analysis phase.

\section{Experimental animals}

Adult male Balb C mice (25-30 g BB) were cultured in the laboratory of Experimental Pathology, Department of Anatomic Pathology Faculty of Medicine, was placed on the condition of 12 -hour light-dark cycle and given pellet diet and tap water ad libitum. All animal-related protocols will be asked to review the application of ethics to the Faculty of Medicine Ethics Committee. Provision of essential oils was based on the method carried out by Muctaridi et al (2011). ${ }^{16}$ Mice were divided into 5 groups (each 5 shrimp) which consists of a control group, a group of stem bark essential oil (dose 0.2 and $1.0 \mu$ / cage), and a group of leaf essential oil (dose 0.2 and $1.0 \mu \mathrm{l} /$ cage). Essential oils are given by way of placing mice in the indoor/enclosed cage measuring $40 \times 40 \times 30 \mathrm{~cm}^{3}$ previously steamed with essential oils as much as 2 times daily for $15 \mathrm{~min}$ before feeding. The treatment period was for 21 days. Every 7, 14 , and 21 days mice were taken for measurement of blood glucose and blood fats. After day 21, mice were sacrificed and dissected for examination of his brain taken hormone metabolic activity in the hypothalamus.

\section{Measurement of body weight and food intake}

Measurement of body weight of mice was measured every day $3 \mathrm{hr}$ after lights on. The amount of food intake was calculated from food left over from feeding twice.

\section{Measurement of blood glucose and lipid}

Measurement of glucose and blood fats are carried out based on the method carried out by Keung et al (2011). ${ }^{10}$ Blood glucose was measured after mice fasted for $16 \mathrm{hr}$ using a glucometer. Blood fat (triglycerides) were measured as glycerol using the spectrophotometric method.

\section{Measurement of the metabolic activity of hormone} secretion response by hormone-receptor binding in the hypothalamus by immunohistochemistry

Brain tissue samples were fixed with phosphate-buffered formalin $10 \%$ for $10 \mathrm{hr}$ at $4^{\circ} \mathrm{C}$, then hydrated in graded ethanol concentrations. Once passed in xylol, made paraffin blocks. Hypothalamic brain tissue sections cut at a thickness of $4 \mu \mathrm{m}$ for immunohistochemistry staining. Once done deparaffination and rehydration, preparations dyed in $0.01 \mathrm{M}$ citrate buffer $(\mathrm{pH} 6.0)$ in a microwave for $5 \mathrm{~min}$. Etched with dosage $3 \%$ hydrogen peroxide to eliminate endogenous peroxide for 5 min at room temperature. Preparations were incubated with antibody of the target protein (a protein produced in response to metabolic hormone secretion - receptor) in PBS for $2 \mathrm{hr}$ at room temperature in a humidity chamber. Further, preparations were incubated overnight at $4^{\circ} \mathrm{C}$. Used as a negative control $\mathrm{N}$ - Universal negative control (Dako). Preparations were then incubated with the appropriate secondary antibody for 1 hour at room temperature, followed by incubation for $30 \mathrm{~min}$ with HRP-conjugated streptavidin. Protein visualized using 3, 3'- diaminobenzidine $(\mathrm{DAB})$ for $10 \mathrm{~min}$ at room temperature. The preparation was added counterstain with Harris Hematoxylin, hydrated and done the mounting.

\section{Molecular Docking}

The process begins with the preparation docking file is done using the docking program contained in the software Autodock Vina. Both ligand and protein molecules, hydrogen were added to both polar and Gasteiger charge while the hydrogen nonpolar were merge. Files are stored in the ligand and the enzyme mole and pdbqt format for later use in the preparation parameters. Dimensional grid box used was $60 \times 60 \times 60$ with a grid spacing of 0.375 Á. Docking calculation algorithm is run with parameters Lamarckian Genetic Algorithm (LGA) with a population size of 150 , as many as 10 million energy evaluations and the repetitions (engine runs) as much as 100 times. These parameters are stored in the format. Pdbqt as a file that will be used to run the docking process.

\section{RESULTS}

\section{Docking simulation}

Simulation methods using in silico tools or software used in the initial screening of bioactive compounds for drug candidates. It is caused by the in silico approach, the interaction between the protein targets of bioactive compounds. To determine the level of interaction with the target bioactive compounds is done by using the approach of docking software AutoDock Vina. Docking as an initial screening process between the molecules of bioactive compounds that can bind to the active site Leptin. Initial screening based on the value of Gibbs energy, $\log \mathrm{P}$, inhibition constants, conformational structure, affinity, efficacy and the bonds between them are simulated. In silico simulation results as described in Table 1. 
Table 1 : Lep-R docking with compounds in cinnamon

\begin{tabular}{ccccc}
\hline Ligands & $\Delta \mathbf{G}$ & Pki & H don/acc & Hbond \\
\hline Benzaldehyde & -7.8740 & 6.580 & 2 & Lys 149, Pro 125 \\
Sinamic acid & -5.6544 & 5.959 & 1 & Val 161 \\
Torreyol & -5.4563 & 4.835 & 1 & Glu 48 \\
\hline
\end{tabular}

Olfactory receptor system targets obtained from the PDB (Protein Data Bank) with PDB code (3V6O). Volatile compounds in cinnamon after extracted and found 30 volatile compounds were analyzed Lep-R docking compounds in cinnamon. Docking process will produce three outputs which can be analyzed further, first the orientation and position of the resulting ligand as an inhibitor of the receptor. The second one can identify compounds that have an affinity for the protein of database compounds available and the third is to predict whether a molecule has an affinity for the receptor. Docking calculation results were seen in the output in the format viewer.mdb.

As shown in Table 1, compound benzaldehyde, cinnamic acid, and torreyol have $\Delta \mathrm{G}$ values lower than other compounds of the lep- $R$. These results indicate that the compound has the above ligand complex conformational stability higher than others. It is confirmed that all three compounds have affinity better than others volatile compounds.

\section{In vivo Test of volatile oil from Cinnamomum burmannii}

\section{Effect of cinnamon essential oil inhalation on body weight of mice.}

Results of cinnamon essential oil inhalation on mice weight every week where week 1 is the weight of mice before inhalation, for each group is the control group, the group of essential oils from cinnamon sticks with doses of 20 and $40 \mu \mathrm{l}$ of leaf and cinnamon with a dose 20 and $40 \mu \mathrm{l}$ is shown in Figure 1 below.

In the Figure 3 can be seen that happen in all groups of mice, including weight gain in the control group from baseline to the end of the study. Highest weight of mice possessed by the control group. The group with a lower weight in order are granting group essential oils derived from the stem with a dose of $40 \mu \mathrm{l}$ and leaves with $20 \mu \mathrm{l}$ dose.

According to the results of statistical tests using two-way analysis of variance, the results obtained are significant differences in the groups tested $(\mathrm{p}=0,00)$. At the smallest difference test using Duncan's test, showed that the control group and the group of essential oils $20 \mu \mathrm{l}$ stem have a higher weight than the group of essential oils $40 \mu \mathrm{l}$ stems, 20 and $40 \mu \mathrm{l}$ leaves. While the provision of essential oils $40 \mu \mathrm{l}$ stems, leaves $40 \mu \mathrm{l}$ and $20 \mu \mathrm{l}$ on the test showed no significant difference. Of two-way analysis of variance test also indicated that there was no difference in body weight of mice in each week conducted the study $(\mathrm{p}=0.608)$. Of these tests also indicated no interaction between group and week in influencing the mice body $(\mathrm{p}=1.000)$.

\section{Effects of inhalation of essential oils of cinnamon on blood glucose levels of mice}

Result of inhalation of essential oils of cinnamon on blood glucose levels of mice every week where week 1 is the weight of mice before inhalation, for each group is the control group, the group of essential oils from cinnamon with doses of 20 and $40 \mu \mathrm{l}$ from stems and leaves is shown in Figure 2 below. In the Figure shows that in all groups there was an increase in blood glucose levels in the control group of mice, including research from the beginning until the end of the study, although the increase is not constant. Blood glucose levels are highest mice belong to

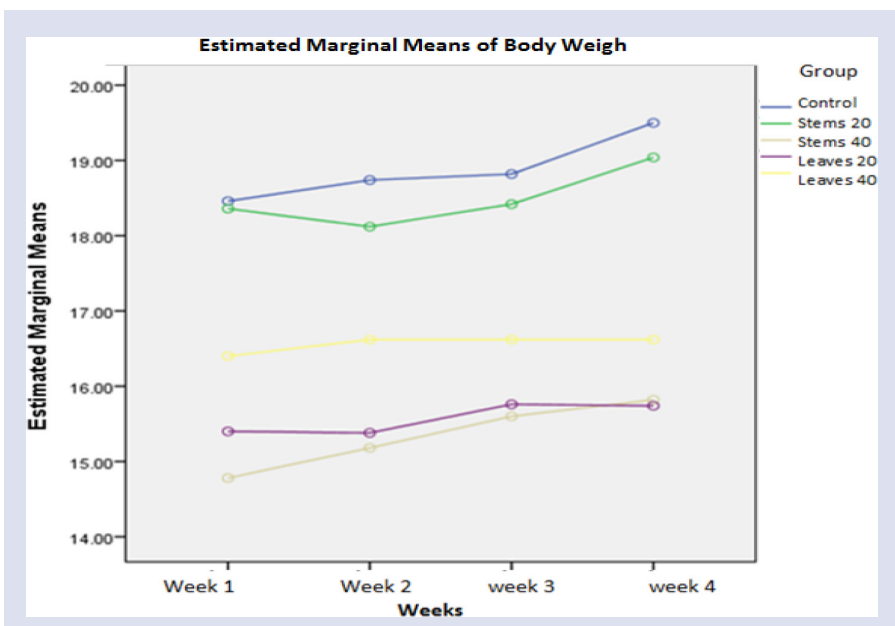

Figure 1 : All groups of mice body weight giving essential oil ( derived from the stems and leaves of $20 \mu \mathrm{l}$ and $40 \mu \mathrm{l}$ ) from the beginning to the end of the study are expressed in grams.

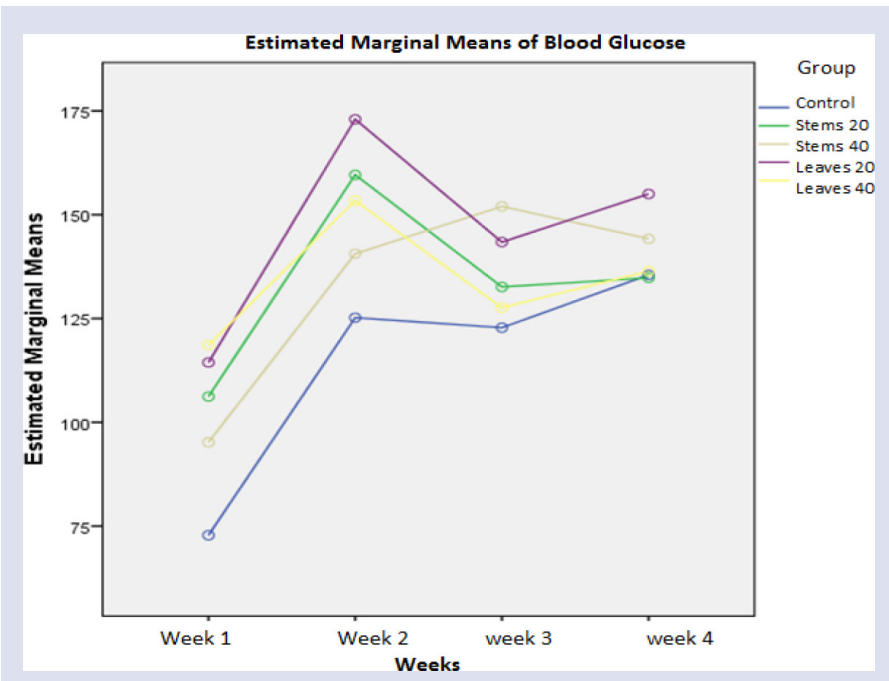

Figure 2 : Blood glucose levels of mice all groups providing essential oil (derived from the stems and leaves of $20 \mu \mathrm{l}$ and $40 \mu \mathrm{l}$ ) from the beginning to the end of the study were expressed in $\mathrm{mg} / \mathrm{dL}$

the group of mice with the provision of essential oils derived from the leaves with a dose of $20 \mu$ l. Other groups who have lower blood glucose levels are a group of essential oils derived from the provision of the stems with doses of 20 and $40 \mu \mathrm{l}, 40 \mu \mathrm{l}$ leaves with a dose of the control group.

According to the results of statistical tests using two-way analysis of variance, the results obtained are significant differences in the groups tested $(\mathrm{p}=0.00)$. At the smallest difference test using Duncan test, it appears that the control group had a different blood sugar levels and significantly lower than the stems with dose 20 and $40 \mu$, and leaves with dose 20 and $40 \mu \mathrm{l}$. While the provision of stem essential oils with dose 20 and $40 \mu \mathrm{l}$ and leaves essential oils with dose 20 and $40 \mu \mathrm{l}$ on the test showed no significant difference. Of two-way analysis of variance test also indicated that there are differences in blood glucose levels of mice in each week doing research $(\mathrm{p}=0.00)$. Of these tests also indicated no interaction between group and week affect blood glucose levels in mice $(\mathrm{p}=0.382)$. 


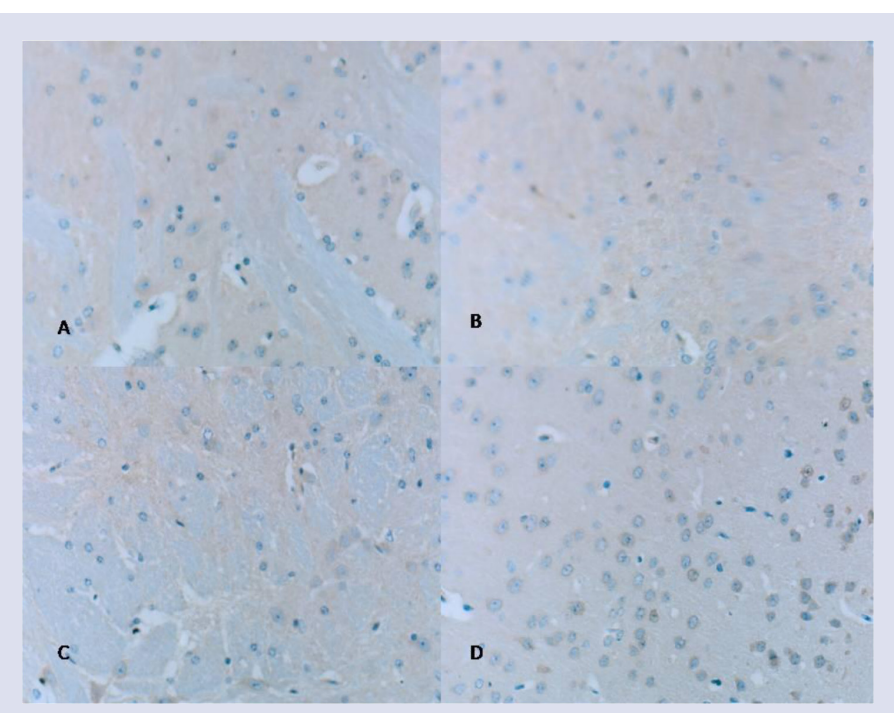

Figure 3 : Staining of immunohistochemical of lep-R in the leaf essential oil doses of $20 \mu \mathrm{l}$ (A) with negative expression, essential oils leaves $20 \mu \mathrm{l}$ $\begin{array}{lll}\text { (B) positive 1, and stems } 40 \mu \mathrm{l} & \text { (C) } 2 \text { positive, and leaves } 40 \mu \mathrm{l} & \text { (D) positive }\end{array}$ 3. Observations were carried out using a light microscope with $400 x$ magnification.

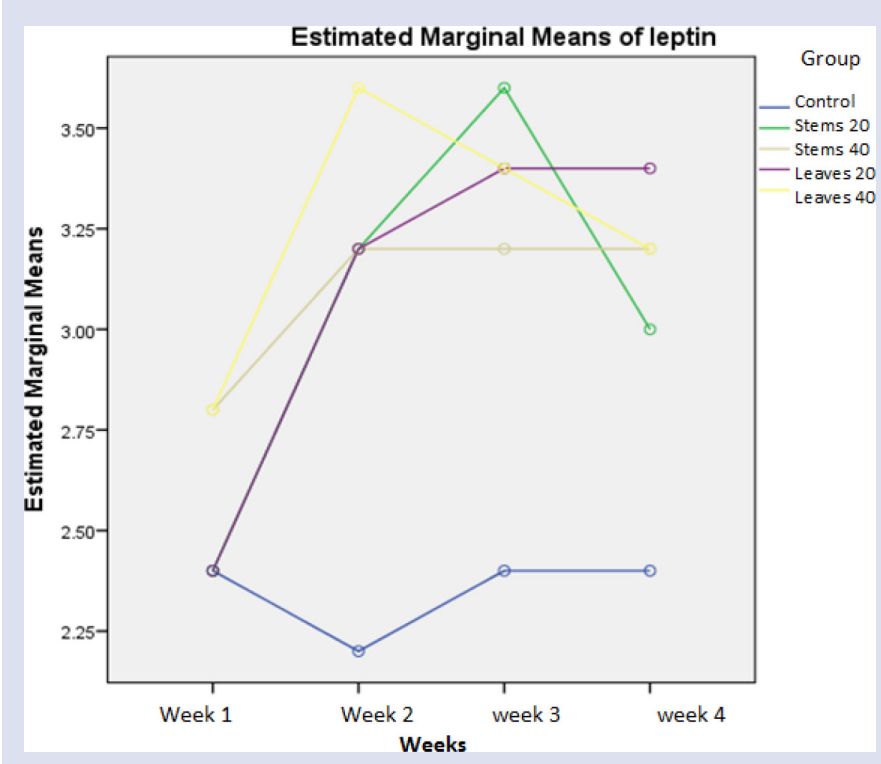

Figure 4 : Expression of lep-R in all groups of mice brain tissue was observed using immunohistochemical methods.

\section{Lep-R expression in Mice Brain Network}

Examination of the expression of the lep-R (Lep-R) in the brain tissue of mice performed using immunohistochemical methods (Figure 3). Ten results on visual field examination were made scores positivity receptor expression as assessed by two researchers (double observer). Positivity declared negative if the ten field of view there is no brain cells at all express hormone receptors. Tested positive for 1, if the field of view of 0-2 cells is positive, tested positive for 2 , if the field of view of 3-5 cells is positive. 3 positive if $5-10,4$ positive if more than ten cells per field of view. Immunohistochemical staining results shown in the following Figure 4.
In Figure 4 above shows that the lep-R (Lep-R) as a whole experienced the differences between all treatment groups with the control group. It appears that the control group had an expression of Lep-R is lower than all group. Whereas among treatment groups, from the graph above does not show the real expression differences. This was reinforced by the statistical test using the Kruskal-Wallis test showed that there are at least one different treatment groups. Through the Mann-Whitney test indicated that the difference between the control group with the other groups. Found no difference between the control group than the other groups.

\section{DISCUSSION}

Effects of agonist or antagonist compounds in cinnamon essential oil on metabolic hormone receptors in the olfactory system are predicted using molecular simulations. Simulation molecules are also used to predict the hormones involved or affected by the content of the compound in cinnamon. Based on the data generated can also be specified target protein response result secretion of the hormone-receptor interactions to be tested by immunohistochemistry.

As shown in Figure 5, compound benzaldehyde able to enter the binding of lep-R and alter conformation. Moreover, compared with the other compounds, compounds benzaldehyde have more hydrogen bonding interactions on lep-R, so it can be said that the compound has the ability benzaldehydee as a lep- $\mathrm{R}$ inisiator.

As Figure 6, the more the hydrogen bonding complex stability and the ability of the stronger inhibition of the active compounds is higher. From Figure 6 looks even further, docking simulation analysis showed that the two compounds that have the amount of hydrogen donor and hydrogen acceptor more than the other compounds. This indicates that the two compounds have a hydrogen bonding interaction is stronger in the lep- $\mathrm{R}$ catalytic than other compounds.

Based on molecular docking results of this assessment, it is possible and reasonable that the compound Benzaldehyde and cinnamic acid is

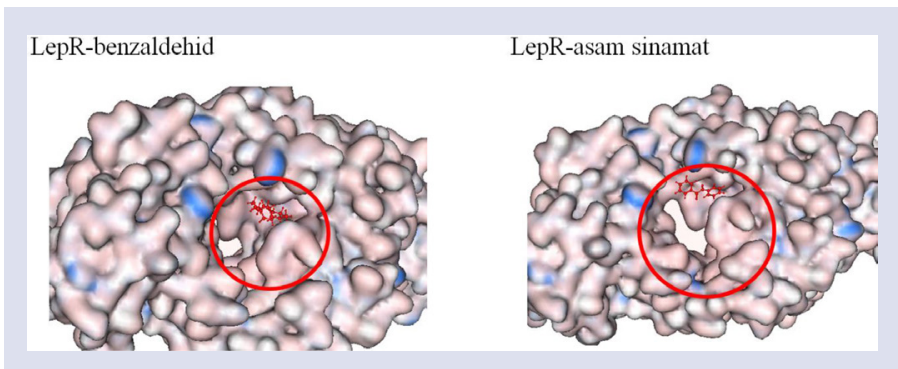

Figure 5 : Complex of LepR-ligands (Benzaldehyde and cinnamic acid) in catalytic side

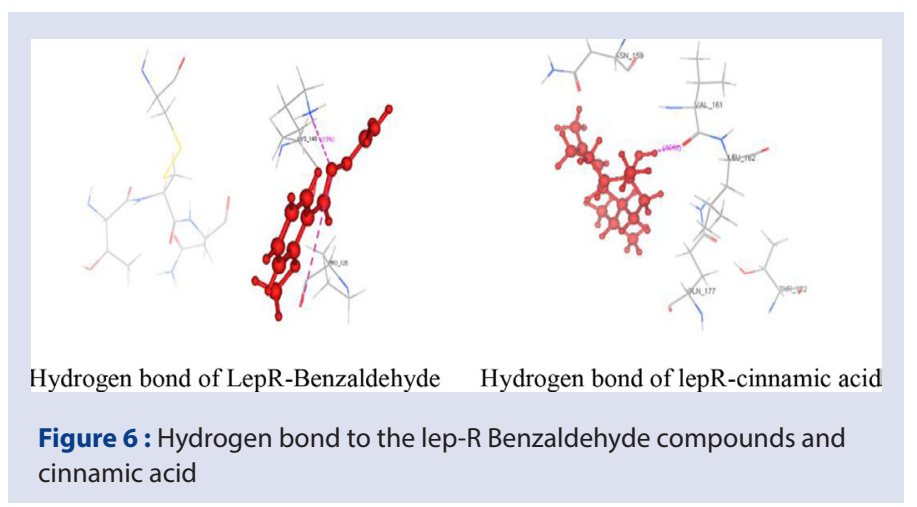


able to hold a bond with Lep-R of the olfactory system, it is extremely grounded and is expected to be a candidate for therapy reduce obesity and reduce appetite in people with obesity.

Results of this in vivo study showed that inhalation of cinnamon essential oil such as leptin administration similar to another researcher that rats were given leptin - a hormone anorexigenic (appetite-suppressing hormone) - exogenous via intracerebroventricular (ICV ) decreased body weight and food intake significantly within 48 hour. ${ }^{8}$ Another study showed that administration of exogenous leptin via ICV in obese mice (mice were given a high-fat diet) then play to lose weight and food intake, also served to increase fatty acid oxidation and increased tolerance glucose. ${ }^{9}$ The effect of weight loss and food intake also occurs in obese rats given exogenous leptin via intranasal..$^{10}$ Based on these studies it can be concluded that the effect of decreasing body weight and food intake by leptin beginning of leptin binding to its receptors on the olfactory system which then affects the activity of the hypothalamus in response to appetite and metabolism.

Lep-R expression in the brains of mice given either inhalation of essential oils derived from the leaves and stems, in contrast to the control group who did not get the essential oils. Provision of essential oils through inhalation increased lep-R expression in the brain of mice. Essential oils derived from the leaves and stems, either with a dose of 20 or $40 \mu$ inhalation, no effects were different from each other.

\section{CONCLUSION}

Both in silico and in vivo evidence that essential oils from cinnamon plants are extracted from Cinnamommum burmannii and given by inhalation in Balb C mice are known to improve glucose and lipid metabolism by reducing the concentration of serum leptin concentrations and increased sensitivity to insulin.

\section{ACKNOWLEDGEMENT}

This research was supported by Directorate of Research and Public Services Universitas Indonesia. And I would like to my gratitude to all those who gave me the possibility to complete this research.

\section{CONFLICT OF INTEREST}

The authors declare no conflict of interest.

\section{ABBREVIATIONS}

Lep-R: Leptin-Receptors; NIDDM: Non-Insulin Dependent Diabetes Mellitus; ICV: Intracerebroventricular; LGA: Lamarckian Genetic Algorithm.

\section{REFERENCES}

1. The Ministry of Health of The Republic of Indonesia. Basic Health Research 2012. Jakarta: The Ministry of Health of The Republic of Indonesia Annual Report. 2013.

2. The Ministry of Health of The Republic of Indonesia. Basic Health Research 2015. Jakarta: The Ministry of Health of The Republic of Indonesia Annual Report. 2016.

3. Pergola GD, Silvestris F. Obesity as a Major Risk Factor for Cancer. J Obes. 2013; 2013: 1-11.

4. Must A, McKeown NM. The Disease Burden Associated with Overweight and Obesity. [Updated 2012 Aug 8]. In: De Groot LJ, Chrousos G, Dungan K, et al., editors. Endotext [Internet]. South Dartmouth (MA): MDText.com, Inc.; 2000-. Available from: https://www.ncbi.nlm.nih.gov/books/NBK279095/.

5. Rolls ET. Review : Taste, olfactory and food texture reward processing in the brain and obesity. Prog Neurobiol. 2015,127-128:64-90.

6. Association for Chemoreception Sciences (AChemS), 37th Annual Meeting, Bonita Springs, Florida, 22-25 April 2015, Chemical Senses, Volume 40, Issue 7, 1 September 2015, Pages 535-668, https://doi.org/10.1093/chemse/bjv029.

7. Bublitz MG, Peracchio LA, Block LG. Why did I eat that? Perspectives on food decision making and dietary restraint. J Cons Psychol 2010. 20: 239-258.

8. Harris RBS. Evidence that leptin-induced weight loss requires activation of both forebrain and hindbrain receptors. Physiol Behav 2013. 120: 83-92.

9. Vu JP, Goyal D, Luong L, Oh S, Sandhu R, Norris J, Germano P M. PACAP intraperitoneal treatment suppresses appetite and food intake via PAC1 receptor in mice by inhibiting ghrelin and increasing GLP-1 and leptin. American Journal of Physiology - Gastrointestinal and Liver Physiology. 2015: 309(10), G816-G825.

10. Keung W, Palaniyappan A, and Lopaschuk GD. Chronic Central Leptin Decreases Food Intake and Improves Glucose Tolerance in Diet-Induced Obese Mice Independent of Hypothalamic Malonyl CoA Levels and Skeletal Muscle Insulin Sensitivity. Endocrinology 2011; 152(11):0000-0000 (online version)

11. Schulz C, Kerstin Paulus K, JÖhren O, and Lehnert H. Intranasal Leptin Reduces Appetite and Induces Weight Loss in Rats with Diet-Induced Obesity (DIO). Endocrinology 2012; 153(1):143-153

12. Al-Jowari SA. Effect of spices mixture onblood glucose and lipids profile in experimentally - induced oxidative stress female rabbits. Iraqi Journal of Science 2012; 53:(2)279-284

13. Peng J, Huan $Y$, Jiang $Q$, Sun S-J, Jia C-M, Shen Z-F. Effects and Potential Mechanisms of Pioglitazone on Lipid Metabolism in Obese Diabetic KKAy Mice. PPAR Research 2014.3: 1-13.

14. Maher Boukhris, Mohamed Bouaziz Ines Feki Hedya Jemai Abdelfattah El Feki Sami Sayadi. Hypoglycemic and antioxidant effects of leaf essential oil of Pelargonium graveolens L'Hér. In alloxan induced diabetic rats. Lipids in Health and Disease 2012;11:81-90.

15. Xuan-Ying Chen, Lin Wang, Xiao-Hua We. Effect of volatile oil from Cinnamomi Cortex on blood glucose and lipid metabolism ininsulin-resistant mice. World Chinese Journal of Digestology 2011; 19(33): 3441-3445

16. Palouzier-Paulignan B, Lacroix MC, Aimé P, Baly C, Caillol M, et al. Olfaction Under Metabolic Influences. Chem. Senses 2012; 37(9):769-797

17. Muchtaridi, Diantini A and Subarnas A. Analysis of Indonesian Spice Essential Oil Compounds That Inhibit Locomotor Activity in Mice. Pharmaceuticals 2011; 4:590-602 